\title{
Global Understanding Classroom: the Innovation of Cross-Cultural Communication English Teaching Qingfang Cao
}

\author{
Feixian Campus, Linyi University, China \\ fxsfcaoqingfang@126.com
}

Keywords: Global understanding classroom; Characterastics; Value; Promotion; Enlightment

\begin{abstract}
The Global Understanding classroom, which originated in the United States, uses various tools such as online videoconferences, chat rooms and e-mail to group students from different countries for real-time and non-real-time communication. It has the characteristics of diversity of disciplines, integrity of courses, school autonomy, student cooperation, and communication situation. This course emphasizes students' intercultural communication ability, promotes the construction of students' English culture patterns, broadens students 'global vision, and can effectively promote English teaching. It is an innovation in cross-cultural communication English teaching. The global comprehension curriculum brings important enlightenment to the teaching of English in China, namely, it attaches importance to the humanism and communicative nature of English, the subjectivity of students and the dominance of teachers.
\end{abstract}

\section{Characteristics and Value of the Global Understanding Classroom}

Global understanding courses have the following main characteristics: Firstly, the diversity of disciplines. It can be used as a compulsory or optional course in a variety of disciplines such as humanities and science at the University. Secondly, the integrity of the course. The entire course needs 45 hours to complete. Thirdly, school autonomy. Each school's credits and teaching content follow its own teaching plan. Whether the global understanding classroom is included in credits or it is only a curriculum supplement is determined by each school. Fourthly, students cooperation. Each student and his partner work together to complete a project related to the topic or profession. The project has a variety of forms, such as topic summaries, news reports, and film analysis. Fifthly, The context of communication. the global understanding classroom provides a "real" world for communication through online video. College students from different parts of the world can conduct real-time video or text conversations, express emotions, and present themselves. The need for youth interaction has been greatly met. Sixthly, Generality in English. All students involved in the connection use English to communicate with each other. English is an important medium for mutual understanding. [1] By the end of 2014, 50 universities or institutions from about 30 countries, including the United States and China, had joined in the project. Nearly 3,000 students worldwide major in the course each year.

The global understanding classroom was originally to help American students understand the curriculum innovation of the world. For Chinese higher education, it is also a new way of English teaching. It cantrain students'ability of listening,spoken, reading, written and translation, and it can also cultivate students' ability of cross-cultural communication. It has promoted the understanding and exchange between Chinese students and students from other countries. It is a beneficial exploration and practice for college English teaching.

The global understanding classroom conforms to the characteristics of the era of globalization and satisfies the desire of people around the world for cultural exchanges. Through carefully designed real-time exchanges among students from different countries, it has become a platform for students from the United States and other English-speaking countries to understand the world. It also provides opportunities for non-native English students to learn English and understand 
different cultures. It is also a teaching innovation in the context of globalization for universities. [2] In this new approach, students are exposed to various cultures, communication becomes faster, and learning becomes more interesting.

The emergence of global understanding courses is based on the development of information network technologies. The material basis for the emergence and existence of global understanding courses is the rapid rise of information technology-- Internet. Nowadays, information network technology has penetrated into all aspects of the young people's working, learning and life. With the rapid development of technology, equipment will be more and more advanced, course discussion will be more and more convenient , scenes will be more and more "real" , and costs will be lower and lower. Most importantly, for each student involved, they can not only learn English but also understand the basic conditions of other countries in the world. In particular, they can understand the thoughts and lives of their peers, broaden their horizons and ideas, and improve their language communication skills. While learning to communicate, students also receive credits for the course, which is also an important reason for the rapid expansion of the course.

\section{Promotion of Global Understanding Classroom for English Teaching}

To improve the communicative ability of students with different cultural backgrounds, English, like other languages, is a tool for communication, a carrier and medium of culture. The purpose of English teaching is to enable students to master this language so that they can better use it at work, study, and life, and improve their understanding of different cultures, world views, values, and social life. The global understanding curriculum is a living classroom and a fresh course. It is a training of English language communication ability. This teaching method has a strong communicative practice.In the classroom, teachers give a theme. Around the theme and in the face of students from other countries with different colors and different accents, students will be more flexible in their mastery of language the understanding of a word is also more profound, and it is more appropriate to use it in different cultures under the guidance of teachers. More importantly, the connected classroom makes the participating students an instant learning whole. Students experience the joy of English learning in instant communication and cultivate the ability to use English to communicate. In this way, the English students learn is living and usable, not characters without spirit, though which to achieve true communication and understanding and advance the innovation of English teaching methods.

It is helpful for students to construct English culture schemata. The obstacle to human communication is not only the various language symbols, but also different cultural schemata in the human brain. The most successful aspect of language education is to establish a deep cultural schema of the language in the learner's brain. so is the highest goal of English teaching. Only in this way can we understand English deeply, use English flexibly, and learn authentic English. In communication among different languages and cultures, because the two sides of the communication come from different cultures, there are great differences in personal experiences, and the cultural patterns in individual minds are also very different. These affect people's choice, understanding, processing and behavior of information.[3]Therefore, the main purpose of cross-cultural English teaching is to reconstruct the meaning structure and cognitive program in English context.We find that through the training of communication, reading, thinking, cooperation, and summing up in global understanding classroom, students'cultural patterns can be effectively reconstructed.

Extend the students'international perspective. English is the most widely used language in the world, and its status is still increasing with the accelerating process of globalization. Using the status of English as a "lingua franca", global understanding classroom design different topics, including social phenomena and hot spots, science and technology education, religion, psychology and spirit, and world development, so that students can enrich their cultural knowledge and deepen 
the understanding to the world. The course achieves multiple goals: to practice language and improve communication skills, to understand the culture, economic and social development of the other country, to understand the ideas of the other's peers, and to introduce the culture of their own country.

Of course, due to the limitations of the network context, it is difficult to achieve in-depth communication in a short period. If the preparation work before the connection, such as vocabulary search, background collection, problem thinking, etc., is not done well, coupled with non-verbal communication and improper use of auxiliary languages by students during communication, it will hinder the effectiveness of the course will be hindered. This is also what global understanding courses need to avoid.

\section{The Enlightenment of Global Understanding Course to Chinese College English Teaching}

The emergence of global understanding classroom inspires our college English teaching, that is, to profoundly grasp the purpose of college English teaching, to combine the characterastic of tools and humanities, to improve the effectiveness of English teaching, and high students' initiative in English learning.

Pay attention to humanism while emphasize the instrumental nature of college English teaching. College English teaching is an important part of foreign language education in China. It is a compulsory public basic course for non-English majors. As students begin professional training, continue to improve themselves and prepare for employment at this stage, students 'learning goals gradually diverge, so the application of college English teaching becomes prominent. At this time, college English teaching must enhance its humanistic nature while realizing its instrumental nature.For the instrumental nature of English teaching, both teachers and students have always paid great attention to it and formed a curriculum system for the cultivation of listening, speaking, reading, writing and translation skills. However, we do not pay enough attention to the humanistic nature of English teaching. The first is to ignore the cultural carrying nature of English as a kind of language. Pay attention to "teaching skills" but ignore "researching theory". The second is to ignore the introduction of our country's excellent culture. Pay attention to "acception"but ignore"output".

The third is to achieve quick results. Pay attention to the realization of instrumental goals but ignore the achievement of humanistic goals.At present, international exchanges are more frequent, political, economic, and cultural exchanges are closer and faster, and people's daily use of English is increasing. So intercultural social communication capabilities are becoming more and more important. The global understanding classroom has inspired us to use advanced Internet technology to enhance its humanistic nature and play the role of English teaching in cultivating talents and spreading culture [4].

Strengthen and improve the communicative English teaching curriculum.English teaching in our country is very instrumental. General English teaching courses and specialized English teaching courses are highly valued, and there are many good experiences that deserve to be continued in teaching practice.For example, under the influence of structuralism, the teaching of English grammar translation as the main line in English teaching is a summary of English language laws by many outstanding scholars and should be further strengthened. Influenced by behaviorism, English teaching uses a large number of exercises as a means to promot students' learning of English. In recent years, under the influence of the concept of communicative nature, some teachers have begun to emphasize context, cooperation and interaction, and engage in meaningful communication. In teaching practice, they not only pay attention to the connotation of words, but also pay attention to the style of written or oral communication, focus on social rationality and fidelity, and avoid over-emphasizing grammatical correctness. The concept of intercommunication guides various kinds of teaching reforms. The foreign language education standards introduced at the beginning of this century--multimedia teaching, computer-assisted teaching, online courses, and 
the reform of college English level 4 and 6, even some schools' introducing of intercultural communication English courses--all these reforms have greatly promoted the practice of English communication.But, the main teaching method of college English is still based on traditional indoctrination. In contrast, the global understanding classroom has expanded the cross-cultural English communication using online video as a medium to different countries and global citizens with different cultural backgrounds. This has not only provided a platform for Chinese college English intercultural communication teaching,but it also provides a model for communicative English teaching. At present, nine universities in our country are involved in this project. Through the comparative analysis of the students, we found that the students'cross-cultural communication motivation, communication and listening skills have been improved significantly, and other cross-cultural communication capabilities have also been improved. Of course, to further strengthen and improve the English intercultural communication teaching curriculum, the global understanding classroom is only a preliminary exploration. Schools can also provide different levels of cultural exchange courses according to the students 'English level and target needs in order to improve their intercultural communication ability in English learning.

Give full play to the principal role of students and the leading role of teachers. In the course of teaching, the leading role of teachers and the main position of students are indispensable. In English teaching, as long as the communicative and practical nature of teaching is enhanced, the main position of students will become more prominent. Students 'internal enthusiasm for learning will be improved, their interest and participation in learning will be greatly increased, and the effect of learning will be enhanced. At the same time, the leading role and responsibility of teachers is even more important. The practice of global understanding curriculum proves that teachers should do a good job in the theme selection, teaching design, and "directing" the entire process in order to achieve teaching goals. [5] The role of teachers 'experience, wisdom and intuition in this creative and critical teaching of English can not be underestimated. Therefore, good teachers should have a multicultural quality and good communication skills. They play a role of guidance and advice in multicultural courses, not a role of explanation.

Special attention should be paid to the cultural collision and ideological differences in cross-cultural communication. Therefore, in the global understanding classroom teaching, we must not only give full play to the main role of students, but also give full play to the guidance of teachers. Teachers should fully analyze the materials used and the topics discussed, and guide students to overcome the obstacles caused by differences in culture and values. At the same time, we should adhere to the correct ideology and value orientation.

\section{References}

[1]Rosina C. Chia, Elmer Poe and Karl L. Wuensch. Attitude Change after Taking a Virtual Global Understanding Course[J]. International Journal of Social Sciences, 2009 (7).

[2]Kachru, Y. World Englishes in Asian Contexts[M] (Larry E. Smith Eds.) Hong Kong: Hong Kong University Press, 2006.

[3]Kramsch, Claire and Steven L.Thorne.Foreign language learning as global communicative Practice.(David Block \& Deborah Cameron Eds.).London: Routledge, 2002.

[4]Svetlana A. Minyurova, Svetlana G. Krylova, Nadezhda S. Ru-denko. Assessment of the Socio-perspective component of intercultural competence: A Pilot Study of Russian Students' View of Amercians [J/OL], 2013-09-12.

[5]Gen L Chang-Wells, Gordon Wells. Constructing Knowledge Together: Classrooms as Centers of Inquiry and Literacy [M]. Portsmouth NH: Heinemann, 1992. 